\title{
EL DISCURSO HIGIÉNICO EN LA PRENSA CONQUENSE DE COMIENZOS DEL SIGLO XX
}

\author{
Alberto GONZÁLEZ GARCÍA \\ Centro de Estudios Sociosanitarios. Facultad de Enfermería de Cuenca. \\ Universidad de Castilla-La Mancha
}

Recibido: $23 / 07 / 2012$

Aceptado: 04/11/2013

\begin{abstract}
RESUMEN: La Salud Pública de principios del siglo XX se caracterizó por la intervención sobre las enfermedades sociales, aquéllas ligadas a las lamentables condiciones de vida y trabajo. Analizamos el contenido periodístico para conocer la higiene pública de este periodo, para valorar cómo la prensa es capaz de alejarse de los centros médicos y gubernamentales y de crear un particular estado de opinión en la sociedad respecto a las enfermedades que responde a los propios intereses de los medios de comunicación. Tomamos como referencia las noticias publicadas en Cuenca relacionadas con las condiciones higiénicas de la ciudad y con el alzamiento del precio de las subsistencias.
\end{abstract}

PALABRAS CLAVE: salud pública, higiene, Cuenca, siglo XX, prensa.

ABSTRACT: Public Health in the early twentieth century was marked by the intervention on the social diseases linked to those deplorable living and working social conditions. We analyze the discursive journalistic contents of this period related to public health, in order to demonstrate how the press is able to get away from medical centers and government and create a particular state of opinion in society about different diseases that respond to the own interests of social mass media. The pieces of news selected were published in Cuenca, and were related to the hygienic conditions of the city and the rise of the subsistence's price.

KEYWORDS: public health, hygiene, Cuenca (Spain), twentieth century, general press.

\section{INTRODUCCIÓN}

El nacimiento de la salud pública española, como una actividad profesional especializada, se produjo en el primer tercio del siglo XX. Su desarrollo estuvo vinculado con la voluntad de modernización de la vida española, fundamentada en la reestructuración de la Administración del Estado que se pretendió realizar en aquellos momentos. Los gobiernos españoles que se sucedieron eran conscientes del atraso sanitario en el que estaba inmersa la nación con respecto a los países de su entorno de Europa Occidental y, más en concreto, en lo que se refiere a la 
incidencia de las enfermedades infectocontagiosas, a las cifras de mortalidad general, también a las deficiencias en los servicios de suministro de agua y alcantarillado urbano y, finalmente, a la ausencia de un sistema efectivo de registro estadístico epidemiológico. Los problemas de salud eran atribuidos a la industrialización y aparecían estrechamente unidos a las lamentables condiciones de vida y trabajo que soportaba una proporción sensible de la población ${ }^{1}$.

Con esta situación, que era calificada por muchos sectores de desastre, vergüenza o deshonra, la sociedad española fue equiparada a un organismo enfermo y degenerado que precisaba un tratamiento adecuado y una formidable regeneración social. Estos impulsos regeneracionistas fueron ganando posiciones en la propia Administración española. En este sentido, la salud pasó a ser considerada como un objetivo social que exigía la regulación de las conductas personales ${ }^{2}$.

\section{HIGIENE Y SALUD PÚBLICA}

La consideración de la enfermedad como un fenómeno colectivo hizo que los fundamentos microbiológicos y fisiológicos de la medicina se combinaran con la medicina social y con la higiene social, que englobaba aquellos saberes y técnicas encaminados a aumentar la salud de la comunidad. En la práctica, la higiene era aquella parcela de ese saber cuyo objetivo se centraba en el conocimiento de las necesidades del ser humano en lo que respecta a su estado de salud como individuo en primer lugar, y como miembro de la sociedad, en segundo término. La microbiología y la preocupación por el saneamiento del medio físico dominaron la actividad sanitaria española durante la primera mitad del siglo $\mathrm{XX}^{3}$.

\footnotetext{
${ }^{1}$ MCneILl, W.H. (1984). Plagas y pueblos. Madrid: Siglo Veintiuno, p. 290. Rosen, G. (1984). «Análisis histórico del concepto de medicina social». En LESKY, E. (comp.). Medicina Social. Estudios y testimonios históricos. Madrid: Ministerio de Sanidad y Consumo, pp. 211-272. Rodríguez Ocaña, E. (2005). Salud Pública en España. Ciencia, profesión y política, siglos XVIII$X X$. Granada: Universidad de Granada. Galiana SÁnchez, M.E. y Bernabeu Mestre, J. (2006). «El problema sanitario de España: saneamiento y medio rural en los primeros decenios del siglo XX». Asclepio, 58 (2), pp. 139-164. Vigarello, G. (2006). Lo sano y lo malsano. Historia de las prácticas de la salud desde la Edad Media hasta nuestros días. Madrid: Abada Editores.

2 Álvarez Antuña, V.M. y García Guerra, D. (1994). «Regeneracionismo y Salud Pública: el bienio de Ángel Pulido al frente de la Dirección General de Sanidad (1901-1902)». Dynamis, 14, pp. 23-42. Rodríguez OcAÑa (2005), p. 235. Beltrán Moya, J.L. (2006). Historia de las epidemias en España y sus colonias (1348-1919). Madrid: La Esfera de los Libros.

3 Rodríguez Ocaña, E. (1987). La construcción de la Medicina Social como disciplina en España (1882-1923). Madrid: Ministerio de Sanidad y Consumo. Rodríguez OCAÑa (2005), p. 89. Vigarello (2006), p. 265. Rodríguez Ocaña, E., Martínez Navarro, F. (2008). Salud pública en España. De la Edad Media al siglo XXI. Granada: Escuela Andaluza de Salud Pública.
} 
Las investigaciones sobre la historia de la salud pública española, concretadas en la historia de la intervención gubernamental sobre la salud de la población ${ }^{4}$, han dividido su desarrollo en cuatro etapas, coincidiendo con determinados sucesos históricos ${ }^{5}$.

En primer lugar el periodo de formación, que abarcó desde 1904 hasta 1925, y que estuvo marcado por los primeros y limitados intentos reformistas. Posteriormente la consolidación del sistema (1926-1957), caracterizada en su intermedio por la Guerra Civil y sus devastadoras secuelas. Estos mecanismos de intervención gubernamental sobre la salud de la población se difuminarían entre 1958 y 1980, lo que constituiría la tercera etapa del desarrollo de la salud pública. Finalmente, tuvo lugar el llamado «renacimiento», a partir de 1980, que estuvo marcado por la Transición y por el influjo de la Conferencia Internacional de Salud de Alma Ata.

Con respecto al periodo en el que centraremos nuestra atención, los inicios del siglo XX, los dos elementos destacables que lo delimitan fueron la promulgación de la Instrucción General de Sanidad en el año 1904 (en época del gobierno de Marcelo de Azcárraga), que generalizó la figura de los inspectores de Sanidad, por un lado; y el Reglamento de Sanidad provincial del año 1925 (promulgado por el Directorio de Miguel Primo de Rivera), por el que se crearon los Institutos Provinciales de Higiene, por el otro 6 .

El rasgo fundamental de este periodo de formación de la salud pública española se caracterizó por la intervención sobre la denominada cuestión social en aquella misma época ${ }^{7}$, esto es, la focalización en cierto número de enfermedades sociales. Las enfermedades sociales designaban situaciones que caracterizaban la organización viciosa de la enfermedad. Desde una perspectiva sociológica

${ }^{4}$ Porter, D. (1999). Health, Civilization and State. A history of public health from ancient to modern times. Londres, p. 4.

${ }^{5}$ Bernabeu Mestre, J., Gascón Pérez, E. (1995). «El papel de la Enfermería en el desarrollo de la Salud Pública Española (1923-1935): la visitadora sanitaria». Dynamis, 15, pp. 151-176. Rodríguez Ocaña (2005), p. 88. Beltrán Moya (2006), p. 231. Rodríguez OcaÑa y Martínez NAVARRO (2008), p. 51.

${ }^{6}$ RodríGUEZ OCAÑa (2005), p. 88.

${ }^{7}$ Miranda Boto, J.M., Velasco Martínez, L. (2011). «La cuestión social desde Cánovas hasta Dato: el nacimiento del Derecho del Trabajo en España a través de los Gobiernos conservadores, 1875-1920». Revista General de Derecho del Trabajo y de la Seguridad Social, 23. 
organicista, se identificó a las alteraciones del orden económico, político y moral de la época con una enfermedad social congénita ${ }^{8}$.

En la práctica, estas alteraciones del orden económico, político y moral que influían sobre la salud se concretaron en tres bloques. El primer bloque englobó las alteraciones relacionadas con el entorno económico e industrial, en tanto que conllevaban la insalubridad de la vivienda, la escasa higiene en el trabajo, los malos hábitos alimenticios y la escasez de subsistencias. En segundo lugar, aquéllas relacionadas con la extensión de la enfermedad o, dicho de otro modo, la propagación social de la enfermedad. En último término se situaron aquellas alteraciones que interferían en la relación entre el capital y el trabajo, en tanto que la enfermedad suponía una pérdida económica para el Estado, ya que el obrero enfermo quedaba fuera de la cadena de producción.

Sobre este esquema higiénico-moral de la etiología social de la enfermedad se articuló eficazmente la formulación bacteriológica, la cual permitía explicar desde el punto de vista microbiológico cómo se agravaba la enfermedad social ${ }^{9}$.

Tradicionalmente, los estudios sobre la higiene y salud pública, enmarcados en este periodo histórico, se centran en señalar cómo se incorpora al imaginario médico profesional esta idea de la higiene como una ciencia social, capaz de resolver los problemas de la comunidad, y la trascendencia de la práctica de los médicos como agentes de regeneración social. Desde esta perspectiva, se ha conseguido analizar cómo la higiene se insertó en el esquema disciplinario del Estado, potenciando intervenciones médicas normativas a gran escala, tratando de redefinir los objetivos y las técnicas de la asistencia sanitaria y la prevención de la enfermedad como fenómeno colectivo. Las fuentes principales que se han utilizado para realizar estos estudios provienen de la Administración y de los textos producidos por los propios médicos de la época ${ }^{10}$.

En la actualidad, se utilizan fuentes obreras para aportar puntos de vista diferentes a partir de las concepciones historiográficas formuladas por la Historia Social. De este modo, el análisis de las mismas pone bien de manifiesto que la

${ }^{8}$ Rodríguez Ocaña (2005), p. 90. GonzÁlez CANalejo, C. (2007). «Cuidados y bienestar: el trabajo sanitario femenino en respuesta a la 'cuestión social'». Dynamis, 27, pp. 211-235.

9 Rodríguez Ocaña (1987), p. 23. Molero MeSA, J. (2004). «Del derecho a 'estar sano' al derecho a la 'salud'. Socialismo y medicina social en el primer tercio del siglo XX español». En Martínez Pérez, J., Porras Gallo, M.I., Samblás Tilve, P., Del Cura GonzÁlez, M. (coords.). La medicina ante el nuevo milenio: una perspectiva histórica. Cuenca: Universidad de Castilla-La Mancha, pp. 1041-1052.

${ }^{10}$ Rodríguez Ocaña y MartíneZ NAVARro (2008), pp. 57-58. 
asimilación de los principios higiénicos en la clase obrera no fue un proceso meramente pasivo, como en muchas ocasiones se ha considerado, sino que constituyó un proceso dialéctico, conflictivo y fuertemente politizado ${ }^{11}$.

Por otra parte, la reconstrucción de la medicina social en torno a la figura del paciente, incluyéndolo así en este complejo sistema, nos permite conocer cómo era percibida en esa época la asistencia sanitaria, la propia construcción cultural de la enfermedad, la experiencia de enfermar y su conceptualización ${ }^{12}$. Finalmente, el estudio realizado en aquellas intervenciones que pretendieron mejorar las condiciones higiénicas de las viviendas y de las infraestructuras, con algunos casos muy señalados como los de Madrid y Barcelona, la denominada ingeniería sanitaria, pone de relieve que los preceptos sanitarios de la higiene social no fueron patrimonio exclusivo de los médicos higienistas ni de la maquinaria del Estado, sino que eran cuestiones que se encontraban planteadas en el debate de las reformas sociales ${ }^{13}$.

\section{PRENSA, MEDICINA, HIGIENE}

La prensa constituye una fuente histórica de elevada significación, ya que este medio de comunicación social ha tenido, y sigue teniendo, un papel muy destacado en la generación de un determinado estado de opinión en la colectividad, en la configuración de la realidad científica, social y cultural, así como en la modificación de las conductas sociales ${ }^{14}$. Este hecho cobra importancia en relación

${ }^{11}$ CAmpos Marín, R. (1997). Alcoholismo, medicina y sociedad en España (1876-1923), Madrid: Consejo Superior de Investigaciones Científicas. CAMPOS MARÍN, R. (2004). «Movimiento obrero, higiene y salud pública en la España de la Restauración. Reflexiones metodológicas». En MARTínEZ PÉREZ, J., pp. 1065-1079. CAMPOS MARÍN, R. (2008). «¿Filántropos o mercaderes? Vacunación antivariólica e intereses profesionales de los médicos en la España decimonónica». En PERDIGUERO GiL, E., VidAl Hernández, J.M. (coords.). Las vacunas: historia y actualidad. Menorca: Institut Menorquí d'Estudis, pp. 83-104.

12 BALlester AÑón, R. (2008). «En primera persona. Los acercamientos historiográficos a la experiencia humana de la enfermedad, siglos XVIII-XX». En ORTIZ GómEZ, T. et al (coords.). La experiencia de enfermar en perspectiva histórica. Granada: Editorial Universidad de Granada, pp. 2734. LeÓN SANZ, P. (2008). «Los relatos de los enfermos: análisis de las quejas de los socios de una sociedad de socorros mutuos». En Ortiz Gómez, T., pp. 51-54. Miqueo Miqueo, C., Fernández DOCTOR, A. (2008). «La consideración del enfermo en la organización de la enseñanza de la Facultad de Medicina de Zaragoza (1880-1936)». En OrTiz GómeZ, T., pp. 81-84.

13 Galiana SÁnChez y Bernabeu Mestre (2006), p. 141.

14 Porras Gallo, M.I. (1998). «Popularizando la medicina en tiempo de la crisis: los médicos y la prensa madrileña durante la epidemia de gripe de 1918-19». En BALLESTER AÑón, R. (ed.). La medicina en España y en Francia y sus relaciones con la ciencia, la tradición y los saberes tradicionales (Siglos XVIII a XX). Alicante: Instituto de Cultura «Juan Gil-Albert», pp. 75-90. 
con las informaciones de tipo sanitario debido al propio interés social sobre las $\operatorname{mismas}^{15}$.

En las primeras décadas del siglo XX, los diferentes medios de comunicación han sido portadores de información médica proporcionada por los propios profesionales sanitarios, sobre todo en relación con los problemas de salud, y en las últimas décadas acerca de los avances en relación con ciertas enfermedades, como por ejemplo respecto al sida. En este sentido, se han desarrollado diversos estudios que han analizado la divulgación de conocimientos científicos en la prensa en periodos históricos muy diferentes, y sobre los que se han aplicado perspectivas variadas $^{16}$.

Ya en 1957 encontramos un análisis detallado con las primeras reflexiones en relación con la forma en la que la prensa recogía y colaboraba en la expansión de la medicina, en relación con las enfermedades mentales ${ }^{17}$. Otro estudio que destacamos, bastante posterior, es el de la utilización de la prensa madrileña como fuente documental para el análisis de la divulgación de los conocimientos científicos médicos durante la epidemia de gripe de 1918-1919. Respecto al contexto socio-sanitario, la prensa jugó un importante papel al menos en dos sentidos: por un lado, esta prensa aspiraba a ocupar una posición más importante en el entramado social español, y veía en la incorporación de elementos científicos a sus contenidos un efectivo mecanismo para lograrlo. Por otro lado, los médicos necesitaban crear una opinión favorable a su actividad, a la vez que debían convencer a la población del alto nivel científico de sus prácticas y de la necesidad de acudir a ellos ante los primeros síntomas gripales, y la prensa posibilitaba aumentar esta presencia y prestigio social y permitía articular ese conjunto de saberes y prácticas en beneficio de su propia legitimidad ${ }^{18}$.

GonZÁlez Silva, M. (2005). «Del factor sociológico al factor genético. Genes y enfermedad en las páginas de El País (1976-2002)». Dynamis, 25, pp. 487-512.

${ }^{15}$ MenÉndez, E.L. y Di PARdo, R.B. (2008). «La representación social negativa de los procesos de salud/enfermedad/atención en la prensa escrita». Salud Colectiva, 4 (1), pp. 9-30.

${ }^{16}$ Entre otras, desde el punto de vista de las relaciones de género. Consúltese SÁNCHEZ, D. «El discurso médico, piedra angular de la construcción de las relaciones de género en la época contemporánea». Asclepio, 50, pp. 63-82.

${ }^{17}$ NAVLET, J. (1957). «Las enfermedades mentales en la prensa popular madrileña (1650-1850)». Asclepio, 9, pp. 357-362.

18 Porras Gallo (1998), p. 77. Betancor Gómez, M.J., Marset Campos, P. (2008). «El papel de la prensa de Las Palmas ante la peste de 1906 en Santa Cruz de Tenerife. Miedo a enfermar o pretexto para reavivar el pleito insular». En ORTIZ GóMEZ, T., pp. 459-462. 
Otra variable tenida en cuenta ha sido la referida a las condiciones sociales en las que se produce la difusión el discurso. De este modo, es necesario conocer el grado de aceptación o rechazo del público a quien va dirigido el discurso, como modo de valorar el grado de efectividad de la transmisión de éste. En la medida en que el discurso médico se mantiene reflejado en la prensa, es de suponer que la demanda social de este discurso existe y que, por tanto, los medios de comunicación siguen interesados en mantenerlo activo. Obviamente, los medios de comunicación no reflejan el discurso como un testimonio histórico, sino para dar a conocer la actualidad del instante, ofreciendo así para nuestro conocimiento la vida cotidiana del momento ${ }^{19}$.

En relación con otros periodos históricos, diferentes autoras abordan la poliomielitis a través de los periódicos $A B C$ y Las Provincias, muy en relación con las últimas líneas de investigación sobre vacunación en el franquismo a través de esta enfermedad concreta ${ }^{20}$. Otros autores, sin embargo, se han centrado en el análisis bibliométrico de revistas sanitarias de esta época como la Revista de Sanidad e Higiene Pública para analizar el grado de institucionalización de la salud pública durante el franquismo, teniendo en cuenta parámetros epidemiológicos, así como el número de publicaciones sobre enfermedades infecciosas, o el número de autores que firman los artículos publicados en las revistas especializadas ${ }^{21}$. Las principales conclusiones de estos estudios señalan que la prensa contribuyó a crear una imagen favorable tanto del régimen franquista, a través de la cobertura vacunal de la poliomielitis, como de los médicos, representando un aparente alto desarrollo científico de la medicina.

Es frecuente, por tanto, la utilización de este medio de comunicación como fuente documental en los estudios históricos contemporáneos para poner de manifiesto cómo la elección de una vertiente más científica de las noticias relacionadas con la salud consolida la posición de la medicina en la realidad social. Así mismo, la consulta sistemática de la prensa obrera y diaria permite poner de relieve cómo se produce la asunción del discurso higienista por parte de los

${ }^{19}$ Villacorta Ortiz, L. (1999). «Hemeroteca Municipal de Alicante: anuncios publicitarios en la prensa alicantina referentes a la salud (1813-1900)». En BENITO LlORIS, À., BLAY MESEGUER, F.X., Lloret Pastor, J. (eds). Beneficència $i$ Sanitat en els municipis valencians (1813-1942). Alcoy: Ajuntament d'Alcoi, pp. 125-137. GonZÁLEZ SiLVA (2005).

20 Porras Gallo, M.I., BÁguena Cervellera, M.J. (2008). «La poliomielitis en la España franquista a través de la prensa general (1940-1975)». En ORTIZ GÓMEZ, T., pp. 325-329.

${ }^{21}$ Marset Campos, P., SÁez Gómez, J.M., Martínez Navarro, F. (1995). «La salud pública durante el Franquismo». Dynamis, 15, pp. 211-250. 
sectores militantes de la clase obrera y por los diferentes partidos políticos ${ }^{22}$. Sin embargo, consideramos de interés analizar el contenido discursivo que no está relacionado con estos centros de poder para poner de manifiesto cómo la prensa es capaz de alejarse de estos emisores de información y de crear un particular estado de opinión en la sociedad respecto a diferentes enfermedades y modo de abordarlas. Este estado de opinión responde a los propios intereses políticos, económicos y sanitarios de los medios de comunicación social.

En este sentido, consideramos de enorme relevancia la incorporación del discurso puramente periodístico como fuente para conocer la higiene pública del primer tercio del siglo XX. Para ello, tomaremos como referencia las noticias publicadas en Cuenca relacionadas con las condiciones higiénicas de la ciudad y con los problemas derivados del alzamiento del precio de las subsistencias. De este modo, contribuimos a incorporar nuevas fuentes en el análisis de la adquisición de principios higiénicos a lo largo del primer tercio del siglo $\mathrm{XX}$, con el objetivo de valorar hasta qué punto los preceptos sanitarios de la higiene social fueron exclusivos de los médicos higienistas y de las Administraciones públicas.

El arranque de la prensa periódica en nuestro país puede situarse en 1833, cuando empezaron a publicarse los boletines oficiales de cada provincia, los cuales nacieron con el objetivo de facilitar la comunicación entre el gobierno y los ayuntamientos. Sin embargo, en el caso conquense el verdadero despegue de la prensa se produciría algo más tarde, entre 1895 y 1913, ligado a la mejora de la red de transportes. El fenómeno periodístico, a diferencia de otras provincias limítrofes, fue prácticamente exclusivo de la capital durante esta época ${ }^{23}$.

El Día de Cuenca fue el único periódico que tuvo publicación diaria durante nuestro periodo de estudio. Este periódico nació en 1914 y se mantuvo hasta el año 1931. Defendió durante toda su existencia un liberalismo moderado ${ }^{24}$. Desde 1914

${ }^{22}$ CAMPOS MARÍN, R. (2011). «El deber de mejorar: higiene e identidad obrera en el socialismo madrileño, 1884-1904». Dynamis, 31 (2), pp. 497-526.

23 SÁnChez SÁncheZ, I. (1986). Castilla-La Mancha en la época contemporánea. Toledo: Servicio de Publicaciones de la Junta de Comunidades de Castilla-La Mancha, p. 112. LóPeZ VillaVERdE, Á.L., SÁNCHEZ SÁnCHEZ, I. (1998). Historia y evolución de la prensa conquense (18111939). Cuenca: Ediciones de la Universidad de Castilla-La Mancha, p. 30.

${ }^{24}$ Este periódico comenzó siendo semanal, para precisamente entre 1918 y 1921 cumplir una primera etapa como diario. Después mantuvo una periodicidad bisemanal y volvió a ser diario en 1926, hasta su total desaparición en 1931. La periodicidad es un elemento importante para medir la incidencia en el público lector y, en principio, se puede establecer una relación entre periodicidad e incidencia en los lectores. Las publicaciones con periodicidad diaria tendrán, por regla general, mayor repercusión en ellos. Las periodicidades diaria, bisemanal y trisemanal iban acompañadas de un 
estuvo controlado por los hermanos Ildefonso, Julián y Joaquín Velasco de Toledo. Los tres hermanos se mostraron partidarios del sistema turnista de partidos durante la Restauración. Con la llegada de la dictadura, apoyarían abiertamente este nuevo régimen, hasta que en 1926 pasara a estar controlado por los hermanos José y Lorenzo Fernández Navarro ${ }^{25}$. Pese a que la mayoría de los periódicos conquenses no tuvo una base económica sólida, entre las empresas periodísticas de vida más dilatada se encontraba, entre otros, este diario.

El Liberal es el único ejemplar de prensa general que, junto al anterior, existió durante el periodo de estudio ${ }^{26}$. Este periódico nació en 1909 y tuvo siempre una periodicidad bisemanal. Su director durante la época que hemos manejado fue Leopoldo Garrido Cavero, hijo del fundador del periódico, D. Leopoldo Garrido y Romero de Segovia ${ }^{27}$.

\section{CONDICIONES HIGIÉNICAS DE CUENCA A COMIENZOS DEL SIGLO $\mathrm{XX}$}

La ciudad de Cuenca es la capital de una provincia que tiene una realidad heterogénea desde el punto de vista demográfico y socioeconómico. A lo largo de los siglos XIX y XX la provincia experimentó un débil crecimiento demográfico pero no uniforme, debido a dos fuertes crisis, la de la epidemia de gripe de 19181919, y en 1939 y años sucesivos, tras la Guerra Civil. Por otro lado, la capital experimentó un fuerte impulso demográfico en los dos siglos anteriores, favorecido por el trasvase de población desde el ámbito rural hacia la capital administrativa, pasando de 7.860 habitantes en 1800 a los 10.756 en el año 1900. Pero ese

contenido básicamente informativo (LÓPEZ VILlAVERDE y SÁNCHEZ SÁNCHEZ (1998), p. 53, p. 70, p. $80)$.

${ }^{25}$ El Día de Cuenca, 23 septiembre 1918, p. 1. Las sagas familiares Velasco de Toledo y Fernández Navarro representaron el periodismo profesional conquense del primer tercio de siglo. Desde finales del siglo XIX y comienzos del XX, los directores y redactores eran representantes de las clases medias que no se dedicaban exclusivamente al periodismo, y que para sobrevivir tenían que realizar todo tipo de funciones en el periódico, escribir frecuentes colaboraciones en prensa local y provincial y ocupar la corresponsalía de distintas publicaciones de difusión nacional (LÓPEZ Villaverde y SÁnChez SÁnCheZ, (1998), p. 103. El Día de Cuenca, 07 mayo 1919, p. 1).

${ }^{26}$ Sin obviar otros ejemplares que tenían un carácter más especializado: El Progreso Conquense (1892-1921), El Centro (1916-1931), El Magisterio Conquense (1908-1923), La Voz del Catecismo (1916-1936) o La Información Médica (1917- 1928) (LÓPEZ VILLAVERde y SÁNCHEZ SÁNCHEZ, (1998), p. 61).

${ }^{27}$ LÓPEZ Villaverde y SÁnChez SÁncheZ, (1998), p. 47, p. 333. El Liberal, 02 noviembre 1918, p. 2. 
crecimiento fue notable en el siglo XX, pues en 1930 ya tenía 15.599 habitantes y en 196027.007 habitantes $(46.047 \text { en } 1991)^{28}$.

Así pues, en los comienzos de siglo, la ciudad de Cuenca tuvo un sostenido crecimiento, aunque el mismo fue más modesto al principio, para tener incrementos más grandes de forma progresiva. Sin embargo, este aumento demográfico en la capital no fue tan elevado en términos relativos, pues la economía provincial no estaba lo suficientemente desarrollada para ello, con limitaciones muy claras en lo que respecta a sectores productivos y una industria casi nula, lo cual no contribuyó, más bien retrasó, el proceso de urbanización que estaba sufriendo la población española en esos momentos ${ }^{29}$.

La comparación con su entorno permite alcanzar una idea más precisa de la realidad. Con respecto al resto de provincias que hoy componen Castilla-La Mancha, Cuenca ocupaba en aquel momento el penúltimo lugar en relación con las tasas de crecimiento demográfico, tanto en lo que se refiere a la escala provincial (en la que sólo superaba a la provincia de Guadalajara), como en lo referido a las capitales, únicamente por delante de la ciudad de Toledo. Sin embargo, eran precisamente las provincias de Cuenca y Guadalajara las que tenían el mayor porcentaje de población activa en esta época ${ }^{30}$.

Durante los siglos XIX y XX la capital conquense experimentó una reorganización socioprofesional del espacio urbano que supuso la pérdida de importancia de la ciudad alta y dio mayor peso a la ciudad baja. En este sentido resultará significativo el testimonio literario de Pío Baroja quien, después de una estancia en la ciudad, plasmó las diferencias entre la ciudad levítica y petrificada, de la parte alta, y la nueva ciudad más dinámica, comercial y burguesa, ligada al eje de la calle Carretería ${ }^{31}$.

28 LóPeZ Villaverde, Á.L. (1997). Cuenca durante la II República. Cuenca: Diputación de Cuenca, p. 25. REHER, D.S. (1988). Familia, población y sociedad en la provincia de Cuenca. 17001970. Madrid: Siglo veintiuno.

29 LÓPEZ Villaverde, Á.L. (2006), «Inmovilismo Versus Modernización en la provincia de Cuenca (siglos XIX y XX)». En Histocuenca. Cuenca en la Historia. Cuenca: Caja Castilla-La Mancha, pp. 111-139, pp. 122-123. GozAlBes Cravioto, E. (2011). Cuenca, territorio y patrimonio histórico-cultural: investigaciones de humanidades. Cuenca: Universidad de Castilla-La Mancha.

30 SÁNCheZ SÁnchez (1986), p. 43. LÓPEZ VILLAVERDE (1997), p. 26.

${ }^{31}$ El texto de Pío Baroja es reproducido en extenso por parte de GiménEz DE AGUILAR, J. (1923). Guía de Cuenca. Cuenca: Museo Local. 
Hasta ese momento, la ciudad alta era el centro de la vida religiosa y de la actividad burocrática ${ }^{32}$. Con el aumento de la población durante esta época, la ciudad baja se convirtió en el lugar de recepción de los inmigrantes, aumentando enormemente su población y concentrándose la mayor parte de la actividad del sector terciario, patrón similar al del resto de ciudades españolas ${ }^{33}$. De esta manera, en el primer tercio del siglo XX, la calle Carretería se convirtió en el nuevo centro urbano donde se instalaron los nuevos edificios públicos, sobre todo en torno al parque de Canalejas, correspondiente al actual parque de San Julián. Por otro lado, los aportes demográficos eran asumidos con la expansión de los barrios populares de San Antón, los Tiradores, los Moralejos y el nuevo barrio de Casablanca ${ }^{34}$.

La asistencia sanitaria en la capital conquense se estructuraba en dos partes. Por un lado, la beneficencia privada, que se llevaba a cabo a través de las hermandades de vecinos de la clase media y proletaria ${ }^{35}$, y de la Junta provincial de Damas de la Cruz Roja ${ }^{36}$. Por otro lado, la beneficencia pública, que quedaba insertada en las administraciones provinciales y municipales. De este modo, encontramos el Asilo Provincial y el Hospital de Santiago, uno de los hospitales más antiguos de España, fundado el 13 de marzo de 1182 por don Tello Pérez y don Pedro Gutiérrez ${ }^{37}$.

A nivel municipal, el Ayuntamiento contaba en la plantilla de la Beneficencia Municipal con tres médicos titulares, cuatro farmacéuticos y cuatro practicantes. Además, la asistencia de necesitados se ofrecía a través de la Casa de Socorro con un médico, un practicante, y un auxiliar de limpieza. En los presupuestos del año 1919 quedó suprimido el cargo de profesora en $\operatorname{partos}^{38}$.

32 El hecho puede verse en el testimonio de los viajeros en VIllar Garrido, Á., Villar GARrido, J. (2004). Viajeros por la Historia. Extranjeros en Castilla-La Mancha, Cuenca. Toledo: Junta de Comunidades de Castilla-La Mancha.

33 RODRÍGUEZ OCAÑa (2005), p. 169.

${ }^{34}$ LÓPEZ VilLAVERDE (2006), p. 123.

35 Troitiño VinUeSA, M.Á. (1984). Cuenca: evolución y crisis de una vieja ciudad castellana. Madrid: Universidad Complutense de Madrid, p. 784.

${ }^{36}$ Las Juntas de Damas tenían la función de vigilar y cuidar en los asilos de maternidad, de expósitos y de huérfanos (ExPósito GonZÁleZ, R. (2010). «Los manuales para la formación de las enfermeras de la Cruz Roja española». En: GonZÁlez CANAlejo, C., MARTínez LóPEz, F. (eds.). La transformación de la Enfermería. Nuevas miradas para la Historia. Granada: Editorial Comares, pp. 311-324). La presidenta de la Junta provincial era Manuela Cañada, esposa del Presidente de la Diputación, José María López Cobo (El Día de Cuenca, 25 marzo 1919, p. 1. El Liberal, 27 marzo 1919, pp. 1-2).

37 Delgado Marchante, A. (2008). «Fuentes documentales del Hospital de Santiago de Cuenca recogidas en el Archivo Histórico Nacional». Hiades, 10, pp. 321-330.

${ }^{38}$ El Día de Cuenca, 19 octubre 1918, p. 1. El Liberal, 12 octubre 1918, pp. 1-2. 
La preocupación principal de la higiene pública giraba en torno a varios elementos relacionados entre sí: el aire como vehículo de salud y enfermedad, la vivienda, y el ciclo del agua ${ }^{39}$. Esta vinculación entre cambio urbano e higiene pública venía produciéndose desde el reinado de Isabel II, cuando alcanzaron enorme protagonismo los planes de reforma interior. De estos elementos surgirían las propuestas para evitar el hacinamiento en los domicilios, disminuir la corrupción aérea, aumentar el espacio libre entre viviendas, el tamaño de las habitaciones y los patios, rectificar el trazado de las calles, y dotar de un sistema de alcantarillado efectivo al casco urbano ${ }^{40}$.

\section{ESTADO DE LAS CALLES}

En Cuenca, el estado sanitario de la ciudad en general era de escasa limpieza por falta de riego, la venta de artículos frescos se llevaba a cabo en la vía pública, y no existía agua corriente en las casas pobres, situación por otra parte muy similar a la descrita en ciudades como Cádiz, Valencia o Madrid ${ }^{41}$. Esta imagen de Cuenca puede verse todavía claramente en la mencionada «Guía» de Giménez de Aguilar, o incluso en el artículo de la voz «Cuenca» (redactada hacia 1922) del Diccionario Iberoamericano («Espasa»).

El ejemplo más claro lo encontramos en las continuas reivindicaciones encaminadas a la pavimentación de la principal arteria de la ciudad baja, la mencionada calle Carretería. La instrucción del expediente de obras para proceder a su pavimentación comenzó en la sesión del Ayuntamiento del 10 de junio de 1918, donde se dio autorización para comenzar las obras, desde el puente de San Antón hasta el camino de la Estación ${ }^{42}$. Sin embargo, las demandas de la prensa y los vecinos venían de tiempo antes ${ }^{43}$, solicitando el riego de la calle al menos dos o tres veces al día para aplacar el polvo, para no encontrar arena en las mesas del casino, en los escaparates del comercio y en los mercados callejeros ${ }^{44}$.

${ }^{39}$ Galiana SÁNCheZ y Bernabeu Mestre (2006), p. 143.

${ }^{40}$ RODRÍGUEZ OCAÑA (2005), pp. 159-164.

${ }^{41}$ Martínez Pons, M. (1995). La epidemia de gripe de 1918 en la ciudad de Valencia. Valencia: Universitat de València. Herrera Rodríguez, F. (1996). «La epidemia de gripe de 1918 en El Puerto de Santa María». Revista de Historia de El Puerto, 17, pp. 31-63. PORRAS GALLO, M.I. (1997), Un reto para la sociedad madrileña: la epidemia de gripe de 1918-19. Madrid: Editorial Complutense.

${ }^{42}$ El Liberal, 12 junio 1918, p. 1.

${ }^{43}$ El Día de Cuenca, 16 mayo 1918, p. 1.

${ }^{44}$ El Día de Cuenca, 17 junio 1918, p. 1. 
En este sentido, fue especialmente la prensa la que se hizo eco de las quejas vecinales publicando que «nos ruegan varios suscriptores interesemos al señor alcalde ordene el riego de Carretería $(\ldots)\rangle^{45}$, llegando incluso a parodiar la situación: «De la Ventilla a Mangana / no se puede transitar, / porque hay más polvo en la calle / que arenas hay en la mar. / De la Ventilla a Mangana / se extiende Carretería; / nadie crea, aunque parezca, /que es zoco de Morería» ${ }^{46}$.

El inicio de las obras se demorará más de un año, a pesar de que el Ayuntamiento obtuvo del Gobierno Central el cincuenta por ciento de la financiación de la obra ${ }^{47}$. La situación de la calle Carretería no será el único motivo de quejas; tal es el caso de los caminos del Martinete y del Puente Verde, camino de Nohales, o el estado de la antigua calle del Rastro, calle sin urbanizar y convertida en auténtico vertedero ${ }^{48}$.

Diversos estudios realizados entre 1913 y 1919 coincidieron en señalar deficiencias generalizadas en cuanto a la escasez de limpieza urbana en las ciudades capitales de provincia, situación que, en la mayoría de los casos, no se solucionó hasta bien entrada la década de los cincuenta. Las intervenciones urbanísticas encaminadas a paliar esta situación se llevaron a cabo a lo largo del primer tercio del siglo veinte, condicionadas por el tamaño de los proyectos, la economía de los consistorios, y las resistencias encontradas en algunos lugares ${ }^{49}$.

\section{VIVIENDA Y HACINAMIENTO}

La preocupación de los higienistas españoles por la vivienda cristalizó en el último tercio del siglo XIX, por entender que la vivienda insalubre y las penosas condiciones urbanísticas de los barrios populares ejemplificaban los principales problemas sanitarios de las mismas: la humedad, la falta de luz y ventilación y, sobre todo, el hacinamiento. Se añadía además el exterior de las casas y las

${ }^{45}$ El Día de Cuenca, 20 marzo 1919, p. 1.

${ }^{46}$ El Día de Cuenca, 16 mayo 1918, p. 1. «De la Ventilla a Mangana» es una sección recurrente de coplejas firmadas por El Tío Corujo, pseudónimo de Julián Velasco de Toledo, redactor jefe y copropietario del diario El Día de Cuenca junto a sus hermanos Ildefonso y Joaquín Velasco de Toledo. Todas las estrofas de estas coplejas comienzan con el verso De la Ventilla a Mangana (El Día de Cuenca, 14 noviembre 1914, p. 1. El Liberal, 05 junio 1918, p. 1).

${ }^{47}$ El Día de Cuenca, 11 julio 1918, p. 3.

${ }^{48}$ El Liberal, 19 junio 1918, p. 1.

${ }^{49}$ RodRÍGUEZ OCAÑA (2005), p. 183. 
elevadas temperaturas en verano, lo cual favorecía la descomposición de las sustancias orgánicas ${ }^{50}$.

Los condicionantes higiénicos, medioambientales y socioeconómicos que definían el medio rural castellano, junto con la falta de higiene y la ignorancia de la población, fueron descritos por los médicos de la época ${ }^{51}$. En el caso de Cuenca las habitaciones, especialmente los dormitorios, se encontraban en un estado regular de limpieza y ventilación, aunque en cierto modo ésta estaba favorecida la mayor parte por la posición elevada. Además, la capital contaba con un elevado número de casas deshabitadas y sin puertas, lo cual favorecía que fueran utilizadas como cuadras o muladares donde almacenar el estiércol de los cerdos, sobre todo en barrios como los del Castillo, Tiradores, San Antón y campo de San Francisco ${ }^{52}$. Tal preocupación por la ventilación y el hacinamiento se hizo patente en las noticias de la prensa sobre los barrios, los distritos pobres y, sobre todo, acerca de la cárcel $^{53}$, lo cual constituía un fiel reflejo del discurso higienista ${ }^{54}$. La ya citada «Guía» de Giménez de Aguilar denuncia la situación de deterioro, pero años más tarde la nueva «Guía» de Julio Larrañaga recogía de forma más suave pero no menos evidente la realidad: sobre todo en la parte alta, los habitantes vivían en barrios enteros que estaban en ruinas ${ }^{55}$.

\section{AGUA POTABLE QUE LLEGA A LA CIUDAD}

Junto al emplazamiento y estado de calles y caminos, también era tenida en cuenta la relación entre enfermedades infecciosas y deficiencias en el uso del agua, ya que los sistemas de abastecimiento de agua y alcantarillado del casco urbano incidían de forma directa en la salud de la población ${ }^{56}$. En 1918, una cuarta parte del total de los más de nueve mil términos municipales de España presentaban

50 Huertas García-Alejo, R. (2002). «Vivir y morir en Madrid: la vivienda como factor determinante del estado de salud de la población madrileña (1874-1923)». Asclepio, 54 (2), pp. 253 276.

${ }^{51}$ Según las crónicas de Mariano Belloguín García, médico rural, en 1925 en su novela Escenas de la vida rural (Galiana SÁnchez, M.E., Esplugues Pellicer, J.X., Bernabeu Mestre, J. (2008). «Escenas de la vida rural: salud y enfermedad en la Castilla de los inicios del siglo XX». En ORTIZ GÓMEZ, T., pp. 55-59).

52 Troitiño VinUESA (1984), p. 783.

${ }^{53}$ El Liberal, 15 marzo 1919, p. 1.

${ }^{54}$ Huertas García-Alejo (2002), p. 261.

55 Larrañaga, J. (1929). Cuenca. Guía Larrañaga, Cuenca. Citamos por la nueva edición de 1966. Ayuntamiento de Cuenca, p. 393.

${ }^{56}$ Galiana SÁnChez y Bernabeu Mestre (2006), pp. 149-150. 
caudales de agua insuficientes y sólo el setenta por ciento de los manantiales que la suministraban eran potables. La cloración del agua se inició por primera vez en 1920, para servir al Hospital Clínico de Barcelona, y a partir de 1925 para el servicio urbano, siendo las ciudades de Barcelona, Sabadell, Reus, Castellón de la Plana y Soria las primeras en incorporar este sistema a la red de abastecimiento urbano $^{57}$.

La Ley de Aguas vigente databa de 13 de junio de 1879, la cual cifraba en 20 litros por habitante y día la cantidad de agua potable que debían proveer los abastecimientos públicos, cantidad insuficiente para las necesidades del momento. En el periodo que nos ocupa, la ciudad contaba con 71 fuentes públicas y particulares con 80 caños, todas ellas surtidas del canal procedente de la Cueva del Fraile $^{58}$.

Además de la cantidad, era indispensable proteger el sistema de abastecimiento con una buena conducción que asegurase unas condiciones de calidad mínimas. En este sentido, gran cantidad del agua procedente de este surtidor se perdía en el trayecto, bien porque carecía de filtros y no tenía limpieza, bien porque se utilizaba furtivamente para lavar, fregar y regar huertas ${ }^{59}$, a pesar de que desde marzo de 1914 se promulgó un Real Decreto por el que consignaban créditos para auxiliar a los abastecimientos de aguas potables de las pequeñas poblaciones ${ }^{60}$. Las denuncias en la prensa conquense no dejaron de existir, con la reivindicación de solucionar las manifiestas deficiencias ${ }^{61}$.

La situación no comenzaría a mejorar, al menos en los barrios principales, hasta mediados del siglo XX, tras casi un siglo de remodelación de proyectos e interrupción de las obras ${ }^{62}$.

\section{ALCANTARILLADO. EL PROBLEMA DEL RÍO HUÉCAR}

La principal causa de morbimortalidad en el setenta por ciento de los municipios españoles era atribuida a la ausencia de un adecuado alcantarillado,

${ }^{57}$ RodríGUEZ OCAÑa y MARTíneZ NAVARro (2008), p. 54.

${ }^{58}$ En la ciudad de Cuenca funcionaba una conducción de agua al descubierto desde la Cueva del Fraile, cuya canalización apenas había sido modificada desde 1531-1532. Esta canalización carecía de filtro y no tenía limpieza alguna (Troitiño Vinuesa (1984), p. 781. SÁnchez SÁnchez (1986), p. 152).

\footnotetext{
59 Troitiño VinUeSA (1984), p. 793.

${ }^{60}$ Galiana SÁnchez y Bernabeu Mestre (2006), p. 153.

${ }^{61}$ GiméneZ de Aguilar, J. Agua va. El Mundo, 09 abril 1912.

62 Troitiño VinUESA (1984), p. 796.
} 
según una encuesta de la Academia de Higiene de Cataluña realizada entre 1903 y $1906^{63}$. El abastecimiento de agua condicionaba en gran medida el sistema de alcantarillado. La importancia o necesidad de una red colectora de aguas era una idea que venía desarrollándose desde $1860^{64}$.

En el caso de Cuenca, si bien en la ciudad alta las alcantarillas podían desaguar con una mayor facilidad gracias a la pendiente, no ocurría lo mismo con la parte baja del municipio, en donde la topografía plana dificultaba el desagüe si no existía una eficaz presión del agua. Desde el año 1875 la ciudad presentaba estas precarias condiciones de higiene, debidas a la incapacidad del Ayuntamiento para resolver los problemas del alcantarillado y el saneamiento del río Huécar ${ }^{65}$.

El establecimiento de una la red colectora de aguas residuales se produjo muy paulatinamente y de forma anárquica, mediante la construcción de tramos aislados en las calles más significativas, allí donde resultaba más fácil hacerlo y donde los vecinos poseían mayor influencia sobre el Ayuntamiento ${ }^{66}$. A comienzos de los años treinta, barrios populares como los de San Antón, el Castillo, Tiradores y el sector sur del Ferrocarril, que albergaban casi un tercio de la población conquense, carecían aún de red de alcantarillado.

El río Huécar ejemplifica las condiciones de insalubridad de la parte baja de la ciudad de Cuenca, pues en él se congregaban todas las deficiencias de la limpieza urbana. Durante siglos este río tuvo un importante papel defensivo (en época medieval el río se embalsaba en su confluencia con el Júcar y formaba una laguna artificial, La Buhaira) e industrial, pues, al margen de un magnífico sistema de huertas en la hoz, albergaba en sus márgenes varios molinos de papel, batanes, lavaderos de lana, molinos harineros y algunas tenerías. Desde que en 1895 se

${ }^{63}$ RodríGUeZ Ocaña y MartínEZ NAVARro (2008), pp. 53-54.

${ }^{64}$ Vigarello (2006), p. 311

65 Troitiño VinUeSA (1984), p. 797.

${ }^{66}$ Durante este período se instauró un fuerte sistema caciquil entre las élites nacionales y locales basado en la arbitrariedad y en la trampa (BLACIK, V. (2009). «De la desinfección al saneamiento: críticas al Estado español durante la epidemia de gripe de 1918». Ayer, 75 (3), pp. 247-273). En nuestra provincia, este sistema permitió la fundación de una serie de cacicazgos estables encabezados por sagas familiares importantes de la región (LóPEZ VILLAVERDE (1997), p. 119). La red caciquil se dejaba notar muy especialmente en la ciudad en diversos ámbitos (El Día de Cuenca, 28 mayo 1918, p. 1. El Día de Cuenca, 28 noviembre 1918, p. 2). La fuerza de la élite conquense y el alejamiento de ésta con respecto a los intereses de la capital del reino ha sido puesta de manifiesto con anterioridad en el ámbito electoral por Gómez Martínez, A., Perales Poveda, M.D. (2005). «Cuenca bajo el caciquismo: elecciones y poder político (1903-1907)». Estudios Humanísticos. Historia, 4, pp. 95119. 
redactase el primer proyecto de desviación del río, hasta que en 1927 se iniciasen las primeras obras, el problema quedará sin resolver $^{67}$.

Dos cartas que remiten al alcalde cincuenta vecinos de las calles Fray Luis de León y Odón de Buen ${ }^{68}$ entre octubre y noviembre de 1918, abordan todas las cuestiones de falta de salubridad del río. Muy presente estaba en el recuerdo del vecindario la epidemia de cólera de 1885 , a raíz del elevado número de defunciones que produjo ${ }^{69}$.

Las quejas de los vecinos se articularon en torno a varios elementos. Por un lado, los malos olores que despedía el río por la confluencia de las alcantarillas de la calle de la Moneda y calle del Rastro, además de los producidos por el lavado de ropas desde el puente de San Pablo al puente del Postigo ${ }^{70}$. La suciedad quedaba acumulada en la presa del Postigo, unida a la procedente de la calle del Corralejo y el callejón de las espaldas de la Casa de Socorro ${ }^{71}$. Por otro, los depósitos de estiércol se almacenaban en el interior de algunos edificios ${ }^{72}$. En este sentido, los vecinos de la calle Calderón de la Barca se quejaban por el incumplimiento de las ordenanzas municipales por parte de un concejal del ayuntamiento, quien en la planta baja de su vivienda albergaba cerdos, lo cual contravenía las ordenanzas municipales $^{73}$. Finalmente, con las crecidas derivadas de las grandes lluvias ocurridas durante el mes de agosto, las aguas contaminadas inundaban la albufera cercana, creando un pantano cenagoso que contaminaba los alimentos.

La solución dada por los vecinos pasaba por hacer desaparecer la presa del Postigo en el río Huécar, cerca del molino de San Martín, hasta su confluencia con

${ }^{67}$ Troitiño VinUESA (1984), pp. 804-806.

${ }^{68}$ El Día de Cuenca, 20 noviembre 1918, p. 2. En la actualidad estas calles han recuperado sus nombres originales, calle de los Tintes y calle del Agua, situadas en el paraje denominado de El Pozuelo.

69 TROITIÑO VINUESA, M.Á. (1982). «La epidemia colérica de 1885 en Cuenca». Olcades. Temas de Cuenca, 9 (2), pp. 135-141.

${ }^{70}$ Contraviniendo el artículo 158 del reglamento de higiene municipal, el cual prohibía lavar en barreños o artesones en la vía pública y arrojar a ella aguas sucias (El Liberal, 26 febrero 1919, pp. 23).

71 Callejón situado entre las calles del Corralejo y la calle del Agua (El Día de Cuenca, 22 octubre 1918, p. 2. El Día de Cuenca, 20 noviembre 1918, p. 2).

72 Troitiño VinUESA (1984), p. 781.

${ }^{73}$ El Día de Cuenca, 25 octubre 1918, p. 2. Entre otras, se incumplían los artículos 155 (los estercoleros estarán situados a una distancia mínima de un kilómetro de la población y 500 metros de los caminos públicos) y 157 (queda prohibido que estén en la vía pública gallinas, pavos y demás animales) (El Liberal, 26 febrero 1919, pp. 2-3). 
el río Júcar; el saneamiento del río desde la Puerta de Valencia hasta su desagüe en el Júcar; la prohibición de arrojar por las calles de la Moneda y Rastro inmundicias al río Huécar; la continuación del alcantarillado en las calles del Corralejo y callejón de la Casa de Socorro hasta el río; y que el alcantarillado de la calle del Agua desaguase en la parte inferior de la presa del Postigo ${ }^{74}$. Por su parte, la prensa proponía la revisión de las ordenanzas municipales: "Cuenca necesita en estos tiempos un vademécum municipal, vigoroso, reciente, calentito, y que se archive ese otro que aunque del año 1906, parece una refundición del 68» ${ }^{75}$.

\section{EL PROBLEMA DE LAS SUBSISTENCIAS EN LA CAPITAL CONQUEN- SE}

Entre 1914 y 1919 la renta por persona disminuyó como consecuencia de la Primera Guerra Mundial, lo cual supuso una crisis del nivel de vida durante estos $a_{n ̃ o s}{ }^{76}$. La no intervención de España en la guerra favoreció un aumento de las exportaciones. Por contra, esto provocó un desabastecimiento del mercado interior, lo cual desencadenó una típica economía inflacionista, donde quedaron seriamente afectados los artículos de primera necesidad. En definitiva, se había desembocado en una crisis de subsistencias en donde la clase obrera fue la principal víctima de la situación ${ }^{77}$.

La economía conquense del primer tercio del siglo XX era agraria, básicamente dedicada al autoconsumo, y de una base industrial muy precaria vinculada a la riqueza forestal y agrícola, por un lado, y a la industria alimentaria de molturación de trigos, aceite y vino, por otro ${ }^{78}$. Los profesionales y las familias que se dedicaban a estas actividades fueron las principales víctimas del proceso inflacionista $^{79}$.

Tal y como hemos abordado en los apartados anteriores, las altas cifras de mortalidad y morbilidad fueron vinculadas a lasituación de insalubridad que

${ }^{74}$ El Día de Cuenca, 22 octubre 1918, p. 2. El Día de Cuenca, 20 noviembre 1918, p. 2.

${ }^{75}$ El Día de Cuenca, 07 octubre 1918, p. 1.

${ }^{76}$ EsCudero, A., SimÓN PÉREZ, H.J. (2003). «El bienestar en España: una perspectiva de largo plazo, 1850-1991». Revista de Historia Económica, 3, pp. 525-565.

77 MARTíneZ Soto, Á.P. (2002). «Salarios, sindicalismo y procesos de negociación en el área vitivinícola del sureste español, 1890-1936». En MARTÍNEZ CARRIÓN, J.M (ed.). El nivel de vida en la España rural, siglos XVIII-XX. Alicante: Publicaciones de la Universidad de Alicante, p. 253.

${ }^{78}$ LÓPEZ VillaVERDE (2006), p. 124.

79 HERRERA RODRÍGUEZ, F. (1996). «Incidencia social de la gripe de 1918-1919 en la ciudad de Cádiz». Llull, 19, pp. 455-470. 
afectaba a todos los ámbitos de la vida de las personas, especialmente al modo y las condiciones de vida, al medio ambiente y a la organización de la salud pública. En este sentido, la higiene se planteó como la solución a los problemas. Las intervenciones se articularon en torno a varias líneas de actuación. Por un lado, los higienistas eran conscientes de que una buena administración sanitaria, con un adecuado presupuesto, junto a una conciencia pública y el saneamiento del medio, eran una inversión de futuro. Por otro lado, el abaratamiento de las subsistencias suponía la intervención más directa sobre la situación socioeconómica de la población, especialmente del proletariado ${ }^{80}$.

Como consecuencia del alza de precios que venía produciéndose desde 1914, en donde el obrero vio disminuido su poder adquisitivo a la $\operatorname{mitad}^{81}$, se creó una Junta municipal de Subsistencias que tuvo que hacer frente a las protestas de proveedores, comerciantes e intermediarios para salir al paso de la situación, tratando de controlar los precios. En junio de 1918 se aprobó la moción de la alcaldía proponiendo la organización de la Junta ${ }^{82}$. A la semana siguiente se fijaron por primera vez los precios de algunas frutas y legumbres, proponiendo las primeras medidas sancionadoras para aquéllos que incumpliesen los precios fijados ${ }^{83}$.

Las críticas a la actuación de la Junta no tardaron en producirse, derivadas de la incapacidad del Ayuntamiento para hacer frente a la influencia de industriales y comerciantes sobre el precio de venta de los artículos. Los funcionarios se vieron incapaces de contener los precios de venta. Ante esta situación, la prensa demandaba al propio alcalde que se cumpliese la ley en defensa de los intereses del vecindario, reclamando para ello órdenes más enérgicas a los miembros de la Junta $^{84}$, y exigiendo a la clase política que legislase en defensa de la clase trabajadora ${ }^{85}$. Desde el punto de vista ideológico, estas demandas se articularon desde presupuestos burgueses, en los que se aunaban la defensa social ante el peligro de la enfermedad y el llamamiento a la reacción social ante la elevación del precio de las subsistencias ${ }^{86}$.

${ }^{80}$ Huertas García-Alejo (2002), p. 257. Galiana Sánchez y Bernabeu Mestre (2006), pp. 143-144, pp. 161-162.

${ }^{81}$ El Liberal, 04 mayo 1918, p. 1.

${ }^{82}$ El Liberal, 05 junio 1918, p. 2.

${ }^{83}$ El Liberal, 12 junio 1918, p. 1.

${ }^{84}$ El Liberal, 19 junio 1918, p. 2.

${ }^{85}$ El Día de Cuenca, 11 febrero 1919, p. 2.

${ }^{86}$ Huertas García-Alejo (2002), p. 266. 
Para ello, se incorporó a las noticias sobre la elevación de los precios de las subsistencias la dimensión personal y subjetiva de los trabajadores. De este modo, aparecieron reflejados en dichos artículos periodísticos los recuerdos personales que definían la historia y las experiencias vitales de la época ${ }^{87}$. Dicho de otra manera, se incorporaron al discurso aquellas características sociales y cognitivas de la realidad social del momento que los hacían más vulnerables y víctimas de la situación económica del momento, tales como la utilización de términos cotidianos como «hogar humilde y huérfano de todo apoyo oficial», o «defender el pan de sus compañeras y de sus hijos» ${ }^{88}$.

Por otro lado, se presentaba a las Administraciones públicas como las culpables de aquel mal endémico de las subsistencias. En primer término el Gobierno Central, por ser incapaz de gestionar la crisis económica derivada de la gran inestabilidad política del Consejo de Ministros ${ }^{89}$. En el caso del Gobierno Municipal, la atención periodística se centró en los graves conflictos que sufrió la capital conquense entre 1918 y 1919.

El primer problema al que tuvo que hacer frente la Junta municipal de Subsistencias fue la negativa del principal sector industrial provincial, los fabricantes de harinas, a producir más género, dada la imposibilidad en que se encontraban de comprar trigo según las tasas fijadas por la Junta municipal. Con esta determinación, se obligaba a los panaderos a interrumpir la fabricación de pan, creando con ello un grave conflicto en la población ${ }^{90}$.Tras diversas negociaciones entre las sociedades obreras, fabricantes de harinas, Gobierno Civil, Alcaldía y representantes del Gobierno Central, se llegará a un acuerdo ${ }^{91}$. Los periódicos se hacían eco de la noticia felicitando a los dirigentes políticos ${ }^{92}$.

La actuación de la Junta municipal de Subsistencias se volverá a poner en tela de juicio a mediados de octubre del mismo año, esta vez, por los comerciantes de la ciudad, que encontraban inadmisibles los precios fijados para diversos artículos ${ }^{93}$. Tras la revisión de los precios para los géneros de mayor consumo, los vendedores

${ }^{87}$ VAN DiJK, T.A. (2003). El discurso como interacción social. Barcelona: Ariel Lingüística, p. 39.

${ }^{88}$ El Día de Cuenca, 20 septiembre 1918, p. 1.

${ }^{89}$ El Día de Cuenca, 06 marzo 1919, p. 1. El Día de Cuenca, 14 abril 1919, p. 2.

${ }^{90}$ El Liberal, 26 junio 1918, p. 1. El Día de Cuenca, 27 junio 1918, p. 2.

${ }^{91}$ El Liberal, 29 junio 1918, p. 2. El Día de Cuenca, 04 julio 1918, p. 1.

92 El Día de Cuenca, 01 julio 1918, p. 1.

${ }^{93}$ El Día de Cuenca, 21 octubre 1918, p. 1. El Liberal, 02 noviembre 1918, p. 1. 
continuaron sin aceptarlos, poniéndose de nuevo en cuestión el principio de autoridad de la Junta ${ }^{94}$. El acuerdo entre la Junta y los comerciantes no llegó nunca a producirse, y sólo cuando se anunció la suspensión de las operaciones de guerra entre los países beligerantes se produjo la bajada de los precios de venta de algunos artículos ${ }^{95}$.

La prensa, como élite simbólica junto a los políticos y científicos, ostentaba el acceso y control de los medios de comunicación y del discurso público ${ }^{96}$. Este acceso preferencial fue utilizado como recurso de poder capaz de mantener la atención de la opinión pública sobre un tema concreto de actualidad ${ }^{97}$.

\section{CONCLUSIONES}

Hemos tomado como referencia algunas acciones relacionadas con la higiene social, enmarcadas en el contexto concreto de la ciudad de Cuenca en las primeras décadas del siglo XX, para comprender cómo los aspectos más locales participan en la configuración de actos sociales de nivel más amplio.

Centrando la atención en las noticias seleccionadas por los diarios de la época, los periódicos tenían como objetivo informar a los ciudadanos acerca de las malas condiciones de higiene de la ciudad, así como de la penosa situación económica de la clase obrera. El carácter progresista de buena parte de la prensa conquense de la época, que durante el periodo analizado defendió un liberalismo moderado y reclamó la limitación de las funciones del Estado a las propias de carácter general $^{98}$, influyó sobre las actitudes populares hacia estos temas.

El discurso de los medios de comunicación escritos hizo que los lectores asumieran las intenciones y los actos como si éstos fueran naturales, normales y existiese consenso, integrándolos como sus propios deseos e intereses. De este modo, aunque las noticias estaban condicionadas por el contexto social, fueron capaces de ejercer influencia sobre el propio contexto y modificarlo. Por tanto, el discurso periodístico que estamos analizando, fue una parte estructural de su propio contexto, y su estructura influyó mutua y continuamente sobre él.

94 El Liberal, 02 noviembre 1918, p. 1.

${ }^{95}$ El Liberal, 20 noviembre 1918, p. 1.

96 VAN DIJK (2003), p. 19-66.

97 VAN DiJK, T.A. (2006). «Discurso y manipulación: discusión teórica y algunas aplicaciones». Signos, 39 (60), pp. 49-74.

98 LÓPeZ VillaVerde y SÁNChez SÁnChez (1998), p. 80. El Día de Cuenca, 05 noviembre 1918, p. 1. El Día de Cuenca, 19 noviembre 1918, p. 2. El Liberal, 03 julio 1918, p. 1. El Liberal, 02 noviembre 1918, p. 2. El Liberal, 11 diciembre 1918, p. 1. 
En el caso concreto que nos ocupa, las razones fundamentales de la mortalidad y mala salud de los habitantes de Cuenca fueron las deficiencias en la pavimentación de la calle Carretería, los focos insalubres del río Huécar y de los estercoleros del barrio de El Pozuelo, y las malas condiciones del alcantarillado de los barrios de San Antón, el Castillo y Tiradores, en la línea de las reivindicaciones de otras ciudades españolas como Madrid, Barcelona o Sevilla. Su análisis nos ha permitido poner de manifiesto que la asimilación de principios higiénicos por parte de la población fue un proceso difícil, polémico y politizado, y de alguna manera en los años sucesivos surgieron iniciativas municipales que abordarían este fenómeno de la enfermedad como cuestión social.

La cuestión de las subsistencias supuso el ejemplo más significativo para sensibilizar a la opinión pública acerca de las condiciones sanitarias del país, constituyendo la intervención más directa sobre la situación socioeconómica de la población. El análisis de las noticias relacionadas con las subsistencias ha puesto de relieve la dimensión personal y la subjetividad del discurso periodístico, además de permitir la explicación del modo en que las estructuras sociales influyen sobre las estructuras discursivas de la sociedad. La inclusión de elementos relacionados con la falta de pan para los hijos durante el conflicto con los fabricantes de harinas de la capital, que hacía a los lectores más vulnerables y víctimas de la situación económica del momento, contribuyó a la movilización y desafío del orden social. 